\title{
QUANDO OS CORPOS E A DIVERSIDADE VÃO ÀS COMPRAS: CONSUMO, ESTEREÓTIPOS E PRÁTICAS DE MERCADO
}

\author{
When bodies and diversity go shopping: \\ consumption, stereotypes and market practices \\ Cuando los cuerpos y la diversidad se van de compras: \\ consumo, estereotipos y prácticas de mercado
}

\author{
Manuela do Corral Vieira \\ Universidade Federal do Pará, Belém, Brasil. \\ Doutora em Antropologia pelo Programa de Pós-Graduação em Antropologia da Universidade Federal do \\ Pará (UFPA) e professora na Faculdade de Comunicação (FACOM) e no Programa de Pós-Graduação em \\ Comunicação, Cultura e Amazônia (PPGCom) da Universidade Federal do Pará (UFPA). Líder do Grupo de \\ Pesquisa Comunicação, Consumo e Identidade - Consia (CNPq/UFPA) \\ E-mail: manuelacvieira@gmail.com
}

\author{
Marcio Monteiro Dias \\ Universidade Federal do Pará, Belém, Brasil. \\ Mestre em Ciência da Comunicação pelo Programa de Comunicação, Cultura e Amazônia (UFPA). \\ Graduado em Comunicação Social - Publicidade e Propaganda pela Universidade Federal do Pará \\ e Integrante do Grupo de Pesquisa Comunicação, Consumo e Identidade. \\ E-mail: marcio.mdias@hotmail.com
}

RESUMO Neste trabalho, busca-se traçar uma investigação com as formas pelas quais os pontos de venda estão recebendo e lidando com a diversidade de seus clientes/ consumidores LGBTI (Lésbicas, Gays, Bissexuais, Travestis, Transexuais, Transgêneros e Intersexuais), a partir de uma etnografia realizada em dois shoppings da cidade de Belém (PA) por meio de uma simulação de compra. O presente artigo, que usa como referencial teórico principal Geertz (1989), Corrêa e Dubeaux (2015), Judith Butler (2006), Louro (1997) e Walter Lippmann (2008), compreende o consumo não apenas como troca de valor monetário, mas como uma das possibilidades de espaços para questionamentos, vivências, debates e práticas simbólicas que perpassam por estereótipos, ações de divulgação de mercado, resistência e interações no tecido social da vida. Assim, o artigo conclui como alguns desses sujeitos se percebem e se apropriam ou não das estratégias publicitárias e de como algumas(uns) delas e deles se motivam, por meio do consumo, a reivindicarem reconhecimento, visibilidade e direitos.'

PALAVRAS-CHAVES Consumo, LGBTI, Publicidade, Estereótipos, Pink Money.

\begin{abstract}
This study investigated the ways in which points of sale are receiving and dealing with the diversity of their LGBTI (Lesbians, Gays, Bisexuals, Transvestites, Transsexuals, Transgender and Intersex) clients/consumers by conducting an ethnography study in two malls in the municipality of Belém, Pará via purchase simulation. Geertz (1989), Corrêa and Dubeaux (2015), Judith Butler (2006), Louro (1997), and Walter Lippmann (2008) are adopted as theoretical framework, where consumption is not only an exchange of value monetary, but one of the possibilities of spaces for questioning, experiences, debate and symbolic practices that are based on stereotypes, actions to publicize the market, resistance and interactions in the social fabric of life.
\end{abstract}


Thus, this article determines how some of these individuals perceive themselves and whether or not they take advantage of advertising strategies and how some of them are motivated to claim respect and their rights by means of consumption.

KEYWORDS Consumption, LGBTI, Publicity, Stereotypes, Pink Money.

RESUMEN: En este trabajo buscamos trazar una investigación sobre las formas en las que los puntos de venta están recibiendo y tratando la diversidad de sus clientes / consumidores LGBTI (Lesbianas, Gays, Bisexuales, Travestis, Transexuales, Transgénero e Intersexuales), desde una etnografía realizada en dos centros comerciales de la ciudad de Belém - Pará, mediante una simulación de compra. El presente artículo, que utiliza a Geertz (1989) y Corrêa y Dubeaux (2015), Judith Butler (2006), Louro (1997) y Walter Lippmann (2008) como marco teórico principal, entiende el consumo no solo como un intercambio de valor. monetaria, pero como una de las posibilidades de espacios de cuestionamiento, vivencias, debates y prácticas simbólicas que atraviesan estereotipos, acciones de divulgación del mercado, resistencias e interacciones en el tejido social de la vida. Así, el artículo concluye cómo algunos de estos individuos se perciben a sí mismos y si aprovechan o no las estrategias publicitarias y cómo algunos (algunos) de ellos se sienten motivados, a través del consumo, a reclamar respeto y sus derechos.

PALABRAS CLAVE Consumo, LGBTI, Publicidad, Estereotipos, Pink Money.

\section{INTRODUÇÃO}

Esta pesquisa tem o objetivo de pensar o consumo para além da compra de uma mercadoria, refletindo a respeito do processo social que está envolvido e a importância das estratégias de comunicação utilizadas pelas marcas enquanto criadoras, inspiradoras e mantenedoras de abordagens que estimulem e criem uma atmosfera favorável ou não para a aquisição desse produto tanto como bem material quanto simbólico. A intenção é fazer uma investigação paralela entre as empresas que fazem ou não campanhas publicitárias voltadas aos LGBTIs (Lésbicas, Gays, Bissexuais, Travestis, Transexuais, Transgêneros e Intersexuais) e os seus pontos de vendas, assim como apresentar um panorama da publicidade como hoje ela comumente mostra-se e como podemos observar algumas empresas que vem trabalhando ou não esses aspectos da diversidade em suas lojas e, neste sentido, foram investigados tanto consumidores LGBTIs quanto os vendedores.

Assim, "o consumo implica, portanto, uma economia moral, cujos pressupostos só são discerníveis quando esmiuçamos as categorias de entendimento que informam nossas práticas e representações sociais” (BARBOSA; CAMPBELL, 2006, p. 39). E tratando-se dos indivíduos LGBTIs, os estudos sobre o consumo dentro dessas perspectivas trazem à tona uma série de discussões, e para entendermos parte delas, propomonos a analisar como se dão algumas dessas práticas com relação a este público no ambiente das lojas de dois shoppings da cidade de Belém, com o objetivo de traçar um panorama sobre a receptividade do mercado aos consumidores LGBTIs, autoidentificados como tais, durante seus processos de compra. Além disso, busca-se compreender quais outros fatores podem influenciar esse consumidor enquanto sujeito que decide, que opera com o dinheiro, dentro das suas escolhas e particularidades, a partir do tratamento recebido. Considera-se ainda o processo anterior à compra, neste caso, as mensagens e os discursos criados e disseminados pelo mercado por meio de imagens e mensagens divulgadas na mídia.

A pesquisa de campo realizada foi de inspiração etnográfica e esteve dividida em dois momentos: visitas às lojas com os(as) interlocutores(as)/ 
mediadores(as) (que foram denominados assim, porque ao mesmo tempo que participam dos diálogos com os vendedores, enquanto consumidores LGBTIs, também tiveram a contribuição de mediá-lo dentro da performatividade que julgaram mais apropriada na exposição da sua orientação sexual, identidade de gênero e seus interesses de compra) e posterior realização de entrevistas com estes sujeitos. O primeiro momento foi desenvolvido a partir de simulações de compra em dois shopping centers, um com público predominantemente das classes socioeconômicas A e B e o outro voltado para os públicos das classes $\mathrm{C}$ e D, ambos localizados na cidade de Belém. A escolha por estes dois espaços amostrais deu-se por conta do questionamento de como um possível recorte, levando em conta as problemáticas ligadas às classes sociais, poderia interferir na forma de atendimento desses mediadores/ interlocutores, assim como, levando em conta o próprio espaço de consumo, se sentiam-se à vontade ou não.

O estudo contou com oito sujeitos que se autoidentificam como LGBTIs, com idades entre 18 e 36 anos, brancas, brancos, negras e negros. A escolha desses sujeitos foi feita com intuito de englobar e compreender da melhor forma possível a diversidade presente entre os membros da comunidade LGBTI. A partir disso, buscou-se em grupos e páginas da rede social Facebook contatar essas pessoas, além da indicação de amigos e participação de pessoas conhecidas, enfatizando a sexualidade por meio da dicotomia homem/mulher e dos demais marcadores sociais de cor/ raça e sexualidade.

Destaca-se ainda que não se revela o nome de nenhuma das lojas visitadas e todas as identificações dos/as interlocutores(as)/ mediadores(as) foram suprimidas por meio de nomes fictícios por questões de privacidade. No dia de cada visita os(as) interlocutores(as)/ mediadores(as) simulavam uma compra, acompanhados de um dos pesquisadores deste estudo. Mencionamos também a forma como os participantes dessa pesquisa estavam vestidos e se apresentavam fisicamente, neste sentido, a percepção do corpo é evidenciada por conta dessas linguagens e significados, conforme pontua Guterres (1995).

As lojas foram escolhidas por entendermos serem de marcas já conhecidas, por investirem em anúncios e estratégias de comunicação voltadas para os LGBTIs nos grandes veículos midiáticos; outras pelo segmento de mercado, como a de joias, por serem locais com produtos de alto valor monetário e consumidores específicos; as de maquiagens e cosméticos, para analisar as questões ligadas à beleza, pois muitos desses produtos são enfatizados e mais consumidos pelo público feminino²; e as lojas esportivas, por supormos que seriam espaços que tivessem algum tipo de estranhamento por conta de toda a construção dos esportes sobre a figura do homem e os estigmas e preconceitos oriundos dessas construções sociais de força, virilidade e masculinidade, além de a maioria de consumidores desses produtos serem do público masculino, segundo pesquisa Sponsorlink, do Ibope Repucom ${ }^{3}$. Foram feitas 4 visitas em dias alternados em cada um dos shoppings, totalizando 12 lojas analisadas em cada.

2. Disponível em: https://www1.folha.uol.com.br/fsp/dinheiro/fi1301200630.htm. Acesso em 2 nov. 2020

3. Disponível em: http://www.iboperepucom.com/br/artigos/um-pais-que-respira-esportes/. Acesso em: 02 de nov. 2020 
No caso das lojas esportivas, por exemplo, com os interlocutores/ mediadores gays, utilizamos a abordagem de estarem procurando um tênis de esportes de força e resistência como o cross fit para os namorados, e para abordagem da lésbica, chuteira para futsal. Sempre tentando trazer provocações a partir da relação desses aspectos sociais que estão binarizados na sociedade, como os esportes, os produtos de beleza, entre outros.

Assim, foi elaborado um roteiro com perguntas abertas, de abordagem (que foi o mesmo utilizado em todos os locais, com as variações necessárias diante de cada situação dentro das lojas) destes interlocutores/mediadores ao adentrarem nos estabelecimentos, buscando observar e compreender algumas das reações dos vendedores às temáticas e situações postas pelos interlocutores/mediadores quando do momento proposto de compra ou de informação de um produto/serviço.

As anotações decorrentes das simulações de compras nas lojas foram feitas utilizando o bloco de notas do celular, como se estivéssemos acessando qualquer outra funcionalidade do smartphone, para evitar despertar qualquer desconfiança entre os vendedores de que se tratava de um estudo. Seguindo os procedimentos da pesquisa, cada visita individual dentro das lojas durou em torno de 20 minutos cada, dependendo muito das interações deles e delas com os vendedores. Posteriormente às simulações de compra, foram feitas perguntas aos interlocutores/ mediadores sobre o que eles haviam achado do atendimento, se sentiram alguma forma de preconceito e se já tinham vivenciado algum tipo de tratamento diferenciado em outras lojas e de como foi essa experiência. Ao final de cada visita procurávamos um lugar mais tranquilo, no qual se pudesse sentar e conversar mais tranquilamente e reservadamente (na maioria dos casos foi a praça de alimentação dos shoppings) para uma entrevista a partir de um roteiro, com o intuito de compreender melhor esses sujeitos. Esta etapa do estudo foi gravada com auxílio do gravador de voz do celular.

Dessa forma, a experiência da divulgação e da compra é compreendida não apenas como troca de valor mercadológico e monetário, mas como uma das possibilidades de debates, vivências e trocas simbólicas que ocorrem com interferência e influência dos demais aspectos que tecem o tecido social da vida em determinados contextos, como a construção de estereótipos e de preconceitos sociais, entendidos a partir do consumo, dos processos comunicacionais e de algumas visitas feitas às lojas, a partir de uma descrição densa dos fenômenos sociais por Geertz (1989) e Corrêa e Dubeaux (2015), da performatividade de gênero por meio dos estudos de Judith Butler (2006) e Louro (1997), pelo entendimento dos processos históricos e sociais de Marina Maluf e Maria Lúcia Mott (1998); representações, apropriações e estereótipos por Walter Lippmann (2008) e Hamilton Carvalho-Silva (2012).

\section{PINK MARKETING: EU CONSUMO, LOGO EXISTO?}

O pink marketing surge como estratégia de mercado para dialogar com o público LGBTI. Esse público é visto com um destacado poder de consum $0^{4}$, o chamado "pink money". E a publicidade, como parte desse

4. Disponível em: http://www.istoedinheiro.com.br/noticias/investidores/20130531/poderpink-money/3262. Acesso em 26 de Mar. 2018. 
fenômeno social que fomenta o consumo, é também coparticipante desse processo do qual o mundo é culturalmente constituído, ainda segundo McCracken (2007):

A publicidade é um meio pelo qual o significado se derrama constantemente do mundo culturalmente constituído sobre os bens de consumo. Por meio da publicidade, bens novos e velhos abrem mão de antigos significados e adquirem outros, novos, constantemente. Como participante ativo desse processo, o espectador/leitor se mantém informado do estado e do estoque atuais do significado cultural existentes nos bens de consumo. Nesse sentido, a publicidade serve como dicionário de significados culturais correntes. (MCCRACKEN, 2007, p. 105)

Nesse sentido, torna-se possível entender a publicidade como meio pelo qual os sentidos culturalmente constituídos podem também ser socialmente e interativamente propagados, sejam esses significados antigos, novos ou ressignificações, tendo como participantes deste processo os sujeitos que podem também criar novas formas de interação, apropriação e desenvolvimento de significados culturais sobre os produtos e serviços consumidos, inclusive por meio da publicidade.

Dentro desse contexto, podemos compreender o consumo como uma ferramenta política, constituído de significados. Como forma de reivindicação de espaços e visibilidade de agendas, no caso dos LGBTIs, eles e elas acabam de alguma forma se aproveitando do pink money e da legitimação por meio dos discursos midiáticos criados sobre esse poder de consumo, como uma forma de resistência e de se fazerem ouvidos. Os desafios de existir como sujeitos abjetos é também perceptível na esfera do social que compreende as práticas de consumo, conforme observou uma das interlocutoras/mediadoras, quando questionada se já havia sofrido algum tipo de discriminação na hora da compra: "a padaria fica absolutamente na frente da minha casa, mas de manhã eu prefiro sair de casa, eu ando 100 quarteirões, eu vou para uma padaria, chego suada em casa mas eu não compro naquela" (Luciana, a partir da pesquisa de campo realizada).

A situação anterior ocorreu após a interlocutora/mediadora não ter sido atendida, mesmo sendo a próxima da fila e, quando questionou, foi tratada no masculino, com um "Ei, cara. Relaxa, tá muito brabo!”. Ela encontrou em seu ato de consumir uma forma de reivindicar o respeito à sua identidade de gênero e deixou de comprar na referida padaria que fica em frente à sua casa. Atitudes que vêm ganhando expressão em diversos segmentos da sociedade e refletindo um posicionamento mais destacado das marcas, seja pela pressão dos consumidores ou como forma de expansão de oportunidades de negócios.

O consumo passa então a ser tido como lugar estratégico em que o poder de modificar e interferir na forma de produção, na visibilidade de demandas de determinados grupos sociais e na comunicação, por exemplo, acabam se tornando possibilidades de lutas e de resistências. O desafio que as marcas têm, dentro deste contexto, é também o de perceber as singularidades das segmentações dos públicos, possibilitando o desenvolvimento de múltiplas formas de constituição dos sujeitos, o que deve/deveria ser feito de maneira empática e responsável, questionando, inclusive, convenções e estereótipos sociais, conforme destaca Iara Beleli, ao tratar dos modelos que criam uma identificação dos sujeitos com as associações feitas nas campanhas publicitárias, visto que "o corpo na publicidade é fundamental para esse processo de 
identificação e, na maioria das vezes, está associado a formulações de gênero e sexualidade" (BELELI, 2007, p. 194).

Assim, corpo e gênero surgem como modelos pré-estabelecidos em que "a propaganda ancorada na diferença sexual revela atributos de gênero. Beleza e força são definidores de feminilidades e masculinidades na publicidade desde o século XIX” (BELELI, 2007, p. 201), e tentar desvencilhar-se dessas questões é ir contra as convenções estabelecidas na sociedade, refletindo diretamente em associações ligadas ao gênero e sexualidade.

O corpo também passa a estar ligado à aparência a partir da identificação proposta por peças de roupas, acessórios, gestos, forma de falar e palavras utilizadas e são definidores das relações sociais estabelecidas dentro dos próprios grupos LGBTIs e na sociedade como um todo. Nesse sentido, o consumo surge como fator essencial que permite essas diferenciações e ao mesmo tempo uma homogeneização, sendo uma forma de inserção dos sujeitos em determinados grupos, com estratégias de consumo "similares" ou da não aceitação de sujeitos por não se adequarem ou parecerem, a ponto de serem identificados como participantes de determinado grupo. Com isso, o corpo é compreendido como um dos principais mediadores das relações sociais a partir das performatividades que irão estabelecer ou não conexões entre os sujeitos e que serão melhor compreendidas a seguir.

\section{O CORPO QUE FALA: CONSTRUÇÃO DO CORPO E PERFORMATIVIDADE}

$\mathrm{Na}$ busca por visibilidade e lutas por direitos, o corpo funciona também como veículo e auxilia na forma de buscar esses interesses, como relatado pela interlocutora/mediadora que é uma mulher trans, quando tem ou não sua identidade de gênero respeitada a partir do uso de roupas e acessórios do tido como feminino. O corpo também é fator relevante nas trocas sociais, como agente ativamente participante no processo comunicativo. Por isso, torna-se essencial entender como são feitas essas constituições dos corpos, especialmente os LGBTIs e das suas performatividades de gênero, assim como as apropriações feitas pelas marcas que buscam criar algum tipo de vínculo com eles e elas. Sobre isso, Judith Butler evidencia:

[...] tenho argumentado que gênero é performativo. Isso significa que o gênero não expressa uma essência interior de quem somos, mas é constituído por um ritualizado jogo de práticas que produzem o efeito de uma essência interior. Eu também penso que o gênero é vivido como uma interpretação, ou um jogo de interpretações do corpo, que não é restrita a dois, e isso, finalmente, é uma mutável e histórica instituição social. (BUTLER, 2006)

O que Butler defende é a questão da performatividade de gênero, ligada a uma construção de sentidos por meio de linguagens e discursos constituídos histórica e socialmente. E o corpo tem função importante nesse sentido, na constituição das características de gênero, uma vez que passa a ser o referencial para as interpretações de gênero, que não é restrita ao masculino e feminino, revelando também aos sujeitos uma identificação ou não com seu sexo atribuído ao nascer. 0 jeito mais delicado é visto então como algo que subverte a lógica do masculino, 
que diz que o homem deve ser mais firme na forma de se portar, e que a delicadeza é tida como um aspecto mais ligado ao feminino como parte de uma construção histórica do papel social do homem, evidenciadas nos estudos de Marina Maluf e Maria Lúcia Mott (1998).

Um dos interlocutores/mediadores, enquanto andávamos por um dos shoppings visitados, relatava do receio de entrar nas lojas em que havia homens vendendo - ele se considera gay, estava vestindo um short lilás estampado com laranjas, usa barba e possui unhas grandes e pintadas falava que tinha mais afinidade com as vendedoras e sentiu certo receio em entrar nas lojas esportivas, queria entrar naquelas que, para ele, poderia ser mais bem recebido, como as de roupas e maquiagens. Esses elementos demarcam a lógica dicotômica da ideia de masculinidade e de feminilidade citada por Guacira Louro: "[...] a lógica dicotômica implica um polo que se contrapõe a outro (portanto uma ideia singular de masculinidade e de feminilidade), e isso supõe ignorar ou negar todos os sujeitos sociais que não se "enquadram" em uma dessas formas" (LOURO, 2014, p. 38).

Em uma das visitas realizadas em simulação de compra, uma interlocutora/mediadora demonstrou certa resistência em ir ao shopping para participar da pesquisa e fazer as simulações de compra. Sua afirmação era que aquele não era lugar para ela, não se sentia bem ali, pois todos a olhavam com um aspecto de julgamento e, de fato, eram perceptíveis os olhares enquanto andávamos pelo shopping. Inclusive sugeriu que fizéssemos a pesquisa no centro comercial da cidade, onde se concentra um número bem maior de pessoas e lojas mais populares. Lá, ela se sentiria mais próxima da sua realidade e passaria até desapercebida no meio de tantas outras pessoas.

O corpo, assim como a roupa que o cobre e protege, transmite significados que estabelecem um processo de comunicação não necessariamente verbal. Isto quer dizer que durante as interações, em inúmeros contextos sociais, os indivíduos levarão em conta as impressões que transmitem aos outros e também a forma como esta comunicação se estabelece. (REIS, 2013, p. 43)

A partir de algumas das visitas foi possível perceber um tratamento diferenciado, não que fosse proposital, mas que talvez denotasse falta de conhecimento do vendedor(a) por não saber lidar com a situação. O que também foi perceptível na fala dos interlocutores/mediadores foi a carência de um alinhamento, algumas vezes, entre os discursos sobre respeito e diversidade construídos por grandes marcas em campanhas publicitárias, mas que nem sempre representam a mesma experiência desses consumidores nos pontos de vendas.

Tendo sido feitas essas observações, entendemos que o treinamento dos vendedores e das vendedoras se torna essencial para conduzir o melhor tratamento possível para clientes transexuais, por exemplo, no intuito de entender a estilização do corpo, seja com a forma de se portar ou vestir, compreendendo como aquele ou aquela cliente expressa sua sexualidade e viabilizar que o processo de comunicação possa ser estabelecido de forma mais saudável possível.

O efeito do gênero se produz pela estilização do corpo e deve ser entendido, consequentemente, como a forma corriqueira pela qual os gestos, movimentos e estilos corporais de vários tipos constituem a ilusão de um eu permanentemente marcado pelo gênero.

(BUTLER, 2003, p. 200) 
Vale a pena ressaltar que a publicidade, como fenômeno social, é capaz de criar e ressignificar as formas de representação dos sujeitos na sociedade, porém, como parte da interação social, não é de forma instantânea e requer uma certa "normalização" dessas representações, o que já vem sendo feito nos últimos anos, quando evita adotar a figura do gay espalhafatoso e cômico e a substitui pela de um ator social comum, com direitos e deveres, por exemplo.

\section{ESTEREÓTIPOS, DESCONSTRUÇÕES E ICONOGRAFIAS LGBTIS}

Mesmo com toda a expansão do consumo LGBTI, este nicho de mercado caminha de maneira lenta no que diz respeito às abordagens nas campanhas publicitárias que não contemplam de maneira ampla a temática, além de serem construídas levando em conta narrativas estereotipadas, que poderão ser analisadas graças a essas construções históricas e sociais. Estereótipos que se valem dessa relação de poder e performatividade de gêneros, consolidados na sociedade em que sempre tentava-se deixar bem estabelecidos os papéis de cada gênero e "correspondia aquilo que era pregado pela Igreja, ensinado por médicos e juristas, legitimado pelo Estado e divulgado pela imprensa" (MALUF; MOTT, 1998, p. 374) nos séculos 19 e 20, e que reproduzem suas intenções nos dias atuais. Percebe-se como os discursos sobre a figura do homem e da mulher, ainda nos dias de hoje, reproduzem vestígios daquilo que eram outrora. Seja com a mulher mãe, esposa, dona de casa, ou representando pessoas LGBTIs, em alguns casos até ridicularizando-os por meio de piadas, ironia e chacotas.

É possível também notar esta conduta ao se estabelecer um padrão estereotipado, uma vez que existem ainda analogias, como por exemplo as ligadas a profissões que estão atreladas ao mundo da moda, maquiagem, cabelo, entre outros, ressaltando esses marcadores sociais construídos em torno da figura feminina submissa e que preza pela beleza e seus artifícios, enquanto a masculina se constrói como postura dominadora. Alguns desses discursos são criados em torno da figura feminina, como nos mostra Denise Bernuzzi Sant’Anna “beleza escrevia-se principalmente no feminino" (SANT'ANNA, 2004, p. 14), ou apresentando uma mulher mais masculinizada, com profissões ligadas ao uso da força física, com a forma de se portar se assemelhando com aquilo que foi construído sobre a figura masculina, desajeitada, rude e nada delicada. Entre tantos outros fatores que ambas as autoras trazem para o cerne das discussões sobre os papéis masculinos e femininos no Brasil, no decorrer dos últimos anos.

Durante a pesquisa de campo, um dos interlocutores/mediadores, relatou que já sofreu bastante com essas construções sobre a figura daquilo que é compreendido como masculino e feminino. Ele possui o cabelo bem grande, alcançando a sua cintura, e segundo seu relato, certa vez, passando em frente a uma loja, o vendedor ficou falando: "é menino ou menina?", algo recorrente e que o deixa irritado, porque sempre soa de forma satírica. Assim também como podemos verificar na fala da interlocutora/mediadora transgênero, quando questionada sobre se sentir representada a partir dos discursos criados nas campanhas publicitárias e nos meios de comunicação:

A mídia, quando ela expõe a pessoa LGBTI, quando não é de uma forma estereotipada, carnavalizada, de chacota, ou então é alguém que venha a poder consumir, mas para consumir, aí tem um recorte de 
classe, tem o recorte de raça, por exemplo, não é todo LGBTI que vai consumir, então quem aparece na propaganda do perfume, do dia dos namorados por exemplo, de uma determinada loja, são os dois homens bonitos, tendo como referência uma estética ocidental, padronizada. (Luciana, a partir da pesquisa de campo realizada)

Para compreendermos os estereótipos presentes nas publicidades e evidenciados na fala da interlocutora/mediadora, torna-se necessário fazermos uma reflexão da apropriação deles como ferramentas da comunicação e sua própria constituição histórica na sociedade. A primeira coisa a evidenciar nas narrativas publicitárias são os arquétipos, que podemos interpretá-los, de algum modo, como sendo precursores dos estereótipos. A partir dos estudos de Carl Gustav Jung, os arquétipos "indicam a existência de determinadas formas na psique, que estão presentes em todo tempo e em todo lugar” (JUNG, 2002, p. 53) e que fazem parte de todos nós em algo muito maior, que é a definição de consciente coletivo, algo que o autor também trabalha.

Esse universo comum a todos é utilizado como fórmula, por assim dizer, da publicidade e ele ajuda a estabelecer a imagem de uma marca, seja pela própria identidade ou por meio de campanhas que fazem uso de artifícios políticos e sociais para poderem atrair a atenção e despertar aquilo de mais interno que as pessoas possuem, seus sentimentos. Assim como auxiliam na subversão de valores fixados na sociedade, como aquilo que é tido como feminino e masculino. Esta também pode ser considerada como a forma encontrada para acessar diferentes nichos e alcançar sujeitos em distintos contextos.

A publicidade e a propaganda fazem uso dos estereótipos como forma de estabelecer relação e comunicação com seus públicos, fazendo uso da representação social por meio de discursos capazes de estabelecerem uma produção de sentido social, mas que trazem consigo juízos de valores, seja de forma pejorativa ou de forma apreciativa. Para Gatti, os estereótipos representam e reproduzem sentidos sociais partindo de ideologias centradas no binarismo homem e mulher. Essas reproduções são provenientes de construções histórico-sociais, reafirmadas em situações como dos discursos publicitários.

Também o estereótipo pode indicar, na medida em que identifica socialmente, uma ligação com certa ideologia (um discurso machista pode mostrar imagens de mulheres frágeis e inferiores intelectualmente, enaltecer a figura do homem etc.). Portanto, o estereótipo pode carregar significados marcados ideologicamente e sócio-historicamente. (GATTI, 2014, p. 400)

André Iribure (2008), em seus estudos sobre as representações das homossexualidades na publicidade e propaganda veiculadas na televisão brasileira, busca entender como essas representações precedem a própria publicidade, assim como percebido no estudo, profundamente na pesquisa de campo, de como os interlocutores/ mediadores se percebiam e se percebem hoje; como eles entendem a complexidade do percurso de lutas sociais e conquistas de direitos para fazerem suas avaliações sobre a apropriação dos LGBTIs nas campanhas das empresas, com o intuito de vender a eles e elas. Para isso, é preciso analisar o contexto, a capacidade de comunicar e as transformações em representações e recortes da realidade que buscam "entender a continuidade, o tempo de conformação da representação social que 
se analisa e o que precede a própria publicidade, o publicitário e seu consumidor" (IRIBURE, 2008, p. 142).

Entretanto, muitas dessas campanhas publicitárias são feitas utilizando estereótipos como uma simplificação de características e que é uso recorrente na publicidade, uma vez que quando se tem um sistema de estereótipos bem fixado, nossa atenção será orientada para apoiar, e o que for estranho será rejeitado. Para Walter Lippmann (2008),

quando um sistema de estereótipos é bem fixado, nossa atenção é chamada para aqueles fatos que o apoiam, nos afastando daqueles que o contradizem. [...] O que é estranho será rejeitado, o que é diferente cairá em olhos cegos. Não vemos o que nossos olhos não estão acostumados a levar em conta. (LIPPMAN, 2008, p. 115)

Com isso entendemos o porquê dos interlocutores/mediadores não se sentirem representados nas campanhas e nos meios de comunicação: "das poucas vezes que tiveram campanhas homossexuais, LGBTI, eu não me senti incluso pelo fato de que as poucas vezes que tiveram, só tinham pessoas LGBTIs brancas e eu nunca me senti representado" (Ramon, a partir da pesquisa de campo realizada). Porque essas campanhas acabam fazendo uso de características como uma forma de simplificação da comunidade, e com apenas isso, acreditam representar toda a diversidade presente na sigla. Só que, em muitos casos, utilizamse apenas gays e lésbicas, ou transgêneros que se assemelhem mais às pessoas cisgêneros (que se identifica com seu gênero de nascimento), na intenção, talvez, de não causar tanto espanto nos setores mais conservadores da sociedade.

Portanto, o gay e a lésbica acabam servindo como base para fazer a representação desse público nas publicidades e até pelo percurso histórico e da posição que se estabelece, a partir desses sujeitos na sociedade. Diferentemente das pessoas transgênero, que por possuírem uma discussão ainda muito recente, acabam sendo incompreendidas e não visibilizadas, ou, quando aparecem, surgem bem próximas da figura cis, parecendo de fato um homem ou uma mulher, sem deixar margem para outras inferências.

Há de se levar em conta, também, a dificuldade na representação desses sujeitos, pois dentro da sigla existe uma diversidade que possui suas particularidades e essas assumem também outras diversidades. De acordo com João Carrascoza (2014), a narrativa publicitária é a forma das empresas se apresentarem no mundo, valendo-se de textos existentes e criando novos, que são difundidos nas mídias por meio dessas narrativas. Assim,

a trama narrativa é construída por enunciados/textos ficcionais ou não e que sua construção parte sempre da experiência dos sujeitos na interação social em um dado momento sócio-histórico: o material da narrativa é o da experiência, já que o “dito” e o "não dito” são escolhas orientadas pela estratégia discursiva - que segue a mercadológica - das corporações que as enunciam. (CARRASCOZA, 2014, p. 109)

O que acaba deixando transparecer que apesar de toda a movimentação econômica e busca por igualdade e direitos, os LGBTIs ainda permanecem invisibilizados e tratados como minorias que não tem expressiva representação no meio publicitário, mercadológico e, acima de tudo, social, deixando a percepção de que "eles só querem vender aquele 
produto, não é algo que estejam tão preocupados em ver como que a gente está sentindo ruim ou coisa assim, não lutam pela causa em si”, conforme a colocação de uma das interlocutoras/mediadoras. Segundo Jorge Leal (2016) não temos campanhas que trazem casais homossexuais para falar sobre educação, segurança no trânsito, imposto de renda, eleições, etc. muito menos casais transgêneros, neste sentido, podemos constatar que "os homossexuais, ao serem relegados à invisibilidade, recebem do Estado um tratamento de não-cidadão” (LEAL, 2016, p. 133).

Ainda é visível a diferenciação e o receio de trazer sujeitos LGBTIs em campanhas publicitárias, pois compreendem e enfrentam os embates políticos a respeito da sexualidade e do gênero estabelecidos na sociedade, assim como perpassam por questões ligadas a essas construções préestabelecidas que colocam os sujeitos em espaços delimitados, ora reforçando estereótipos, ora desconstruindo-os. A relação entre visibilidade e representatividade ainda é muito tênue, pois a apropriação dos sujeitos LGBTIs acaba ficando atrelada a discursos publicitários, feitos com o intuito de alcançar este público enquanto consumidores, salvos algumas empresas que já possuem políticas de inclusão dessas pessoas em seus ambientes de trabalhos.

A tentativa de algumas marcas de se apropriarem de discursos e temáticas que integram, em contextos mais amplos, agendas políticas, refletem a maneira como muitas delas vêm buscando se adequar ao mercado pela via das questões sociais. Deixando até um pouco de lado os atributos e qualidades ligados aos produtos e serviços e construindo suas narrativas publicitárias em torno do próprio consumidor, não simplesmente como aquele que consome de forma supérflua, como muitos ainda veem o consumo, mas como sujeitos que operam suas ações direcionando-as de forma mais engajada com a realidade em que vivem.

Por outro lado, compreendemos essas estratégias de comunicação em um viés dicotômico, em que, se por um lado as pautas LGBTIs ganham visibilidade, ainda que em uma amplitude reduzida, por outro, o mercado passa a absorver esse público como potenciais consumidores. Tendo em vista que essa apropriação pode não ser tão espontânea quanto parece, mas está atrelada aos interesses de mercado e também às mudanças ocorridas nos últimos anos, em que a internet propiciou uma expansão na forma de se comunicar entre empresas e clientes, como sendo o cliente um participante muito mais ativo e reivindicando cada vez mais seu espaço e respeito enquanto consumidor.

\section{CONSIDERAÇÕES FINAIS}

Este estudo buscou uma melhor compreensão das relações sociais e de consumo, dentro e fora da população LGBTI, em especial a forma como alguns desses sujeitos se percebem e se apropriam ou não dessas estratégias publicitárias e de como algumas(uns) delas e deles se motivam por meio do consumo a reivindicarem o respeito e seus direitos. Percebe-se que a publicidade, enquanto fenômeno social, é capaz de motivar significados e tendências na sociedade, e nessa busca por expansão, as marcas têm um papel fundamental quando investem em uma proximidade cada vez maior com seus públicos e na forma como contribuem com a visibilidade e a propagação de discursos sobre às diversidades, ainda que algumas se limitem apenas em evidenciar o corpo como forma de delimitar esses papéis. 
Entende-se que as marcas precisam buscar um alinhamento do seu posicionamento nas campanhas até o atendimento no ponto de venda, pois como visto em algumas simulações, a discriminação e preconceito também se fazem presentes nesses espaços e mesmo que determinada marca invista em publicidades que tratem sobre pessoas LGBTIs, se não houver uma apropriação desse discurso entre os colaboradores no momento da venda, pode ser que todo investimento não surta o efeito esperado. Pois, no momento da venda na loja, o(a) vendedor(a), mesmo como representante da marca, pode agir a partir de suas vivências e interpretação de mundo acerca da diversidade sexual e de gênero, sem saber como lidar da maneira correta, como visto neste estudo.

Assim, o consumo surge como um grande espaço para esses questionamentos, vivências, debates e práticas simbólicas no tecido social, não apenas como a aquisição de um bem material ou simbólico mas como parte constituinte do processo que envolve muitas outras questões ligadas às relações sociais, que vão além da troca de valor monetário e que perpassam por estereótipos, ações de divulgação de mercado, resistência e interações na sociedade.

\section{REFERÊNCIAS}

BACCEGA, M. A. Inter-relações comunicação e consumo na trama cultural: o papel do sujeito ativo. In: CARRASCOZA, J. A.; ROCHA, R. M. (org.). Consumo midiático e culturas da convergência. São Paulo: Miró Editorial, 2011.

BARBOSA, L.; CAMPBELL, C. O estudo do consumo nas ciências sociais contemporâneas. In: Cultura, Consumo e Identidade. Rio de Janeiro: Ed. FGV, 2006.

BELELI, lara. Corpo e identidade na propaganda. Estudos Feministas, Florianópolis, v. 15, n. 1, p. 193-215, 2007. Disponível em: https://periodicos.ufsc.br/index.php/ref/article/view/ S0104-026X2007000100012. Acesso em: 19 ago. 2018.

BUTLER, J. Problemas de gênero: feminismo e subversão da identidade. Rio de Janeiro: Civilização Brasileira, 2003.

BUTLER, J. O gênero é uma instituição social mutável e histórica. Revista IHU On-Line, São Leopoldo, n. 199, ano 6, p. 3-5, out. 2006. Disponível em: http://goo.gl/wsokQ. Acesso em: 19 ago. 2018.

GATTI, M. A. Estereótipo e pré-construído: é possível uma articulação?. Revista Signótica, Goiânia, v. 26, n. 2, p. 397-414, 2014. Disponivel em: https://dialnet.unirioja.es/descarga/ articulo/6322849.pdf. Acesso em: 22 jan. 2019

GUTERRES, L. S. O corpo carnavalesco. In: LEAL, O. F. (org.). Corpo e Significado: ensaios de antropologia social. Porto Alegre: Editora da UFRGS, 1995.

IRIBURE, A. As representações das homossexualidades na publicidade e propaganda veiculadas na televisão brasileira: um olhar contemporâneo das últimas três décadas. 2008. Tese (Doutorado em Comunicação e Informação) - Faculdade de Biblioteconomia e Comunicação, Universidade Federal do Rio Grande do Sul, Porto Alegre, 2008.

JUNG, C. G. Os arquétipos e o inconsciente coletivo. Petropólis: Vozes, 2000.

LEAL, J. T. B. A publicidade gay no Brasil: do silêncio à conexão. Rio de Janeiro: Pirilampo, 2016. LIPPMANN, W. Opinião pública. Petrópolis: Vozes, 2008.

LOURO, G. L. Gênero, sexualidade e educação: uma perspectiva pós-estruturalista. Rio de Janeiro: Vozes, 2014.

MALUF, M; MOTT, M. L. Recônditos do mundo feminino. In: SEVCENKO, N. (org.). História da vida privada no Brasil: república da belle époque à era do rádio. São Paulo: Companhia das Letras, 1998. p. 368-421.

VIEIRA, M. C. Os jovens flâneurs.com: a construção e a liquidez da identidade no espaço das redes sociais da internet. 2013. Tese (Doutorado em Antropologia) - Universidade Federal do Pará, Belém, 2013. 
MCCRACKEN, G. Cultura e consumo: uma explicação teórica da estrutura e do movimento do significado cultural dos bens de consumo. Revista de Administração de Empresas, Boston, v. 47, n. 1, p. 99-115, 2007. Disponível em: http://www.scielo.br/pdf/rae/v47n1/a14v47n1. pdf. Acesso em: 21 fev. 2019.

PELÚCIO, L. Breve história afetiva de uma teoria deslocada. Revista Florestan, São Carlos, n. 2, p. 26-45, 2014. Disponível em: https://goo.gl/5DsfJo. Acesso em: 1 fev. 2019.

REIS, D. N. Homens distintos, consumo, construção do corpo e identidade gay viril. 2013. Dissertação (Mestrado em Ciências Sociais) - Faculdade de Filosofia e Ciências Humanas, Pontifícia Universidade Católica do Rio Grande do Sul, Porto Alegre, 2013.

SANT’ ANNA, D. B. História da beleza no Brasil. São Paulo: Contexto, 2014. 